\title{
Analyzing Curriculum as Participant Perspectives
}

\author{
Catherine D. Ennis \\ University of Maryland
}

\begin{abstract}
For this study, curriculum was defined as a holistic set of perspectives that interact to create the educational environment. The Goodlad et al. (1979) domain concept was used as the theoretical structure for the examination of content in three elementary physical education programs. Two of the programs used a movement education curriculum (Logsdon et al., 1984) while the third was structured based on a traditional activity or sport and games approach. Data collection consisted of an examination of documents (ideological and formal domains), interviews with teachers and students (perceived and experiential domains), and observation (operational domain). Data were analyzed using constant comparison. The ideological domain was found to be the most influential curriculum perspective in these programs. Major differences were detected in the use of shared decision-making and in the students' cognitive involvement with the content.
\end{abstract}

School curricula typically reflect a combination of participant philosophies. This blending of viewpoints, assumed to be present in the original development of a curriculum document, is equally influential in the implementation of the program in the school setting. Administrator, teacher, and student decision-makers act and react to a collection of personal understandings or perceptions of events within the educational environment (Zeichner \& Tabachnick, 1983). Because curriculum development and implementation are essentially person-based undertakings, the beliefs, values, and experiences of these decision-makers interact to form the curriculum process. The study of curriculum in schools is a complex undertaking. Curricular information exists in the form of documents, events, behaviors, impressions, and experiences. John Goodlad and his associates (Goodlad, Klein, \& Tye, 1979) have developed a model for viewing curriculum as a series of perspectives on the teaching/learning process. The model was developed in conjunction with the Study of Schooling, a national research project, reported

This research was funded by a grant from the Wisconsin Alumni Research Foundation.

Catherine D. Ennis is with the Department of Physical Education, PERH Bldg., University of Maryland, College Park, MD 20742. She was on the faculty at the University of Wisconsin-Madison at the time this research was conducted. 
in a series of ERIC documents. ${ }^{1}$ The research reported here used this model to analyze three physical education curricula as a synthesis of participant perspectives.

Goodlad and his colleagues have proposed five perspectives or domains that contribute to the understanding of curricula in school settings. The ideological domain includes the philosophy and explicit assumptions of the school program. This domain represents the convictions and values of content experts outside the school district. Textbooks or other curriculum packages that have been formally adopted by the district are the most common examples of this domain. The formal domain consists of documents that have been developed inside the school system and officially approved by the curriculum coordinator, school board, or other governing agent. The curriculum guide is the most common form of documentation in this domain. The teacher's philosophy, lesson plans, and personal interpretations of what is taught and learned in the classroom are conceptualized within the perceived domain. The teacher's values and experiential background appear to play a major role in conceptualizing this perspective (Goodson, 1985).

The experiential domain reflects the perspective of the student. Achievement is the most widely publicized product of student experience in this domain. Advocates of a more holistic perspective (e.g., Apple \& Beyer, 1983; Hellison, 1985; Kolb, 1983) emphasize the relevance of self-efficacy, cognitive style, and student attitude as influential in the learning process. The fifth perspective, the operational domain, is limited to behaviors exhibited by program participants and witnessed by outside observers. It reflects behaviors of teachers and students within the teaching/learning process.

Goodlad and his colleagues have suggested that all five perspectives interact to form the holistic curriculum. These interactions serve to either affirm or contradict the influence of any single domain. For example, the ideological philosophy officially approved by the school board may be adapted to fit the needs of the community when it is written into the curriculum guide (formal domain). The teacher's beliefs about children, instruction, or subject matter (perceived domain) may consciously or unconsciously conflict with the curriculum guide, producing modifications as the content is conveyed to students (Ennis, 1985). Students may experience different content and learn different lessons than the teacher intended (Graber, 1988; Wang, 1977).

The purpose of the present study was the examination of curricular perspectives in traditional and movement-based elementary programs. Specifically, the research question addressed the extent to which each domain contributed to the philosophical rationale for the program as represented by curriculum content decisions. Three separate programs were examined in this study. An effort was made to study programs of high quality. Programs based on the Logsdon et al. (1984) curriculum approach were selected as examples of movement curricula. The Logsdon model was chosen because of the completeness of the curriculum documentation available to teachers, curriculum specialists, and researchers.

${ }^{1}$ Reports of individual research studies conducted as part of the Study of Schooling are available as ERIC documents ED 214875 through ED 214895. 


\section{Method}

\section{Subjects}

Three teachers were selected for the study based on the criteria of professional involvement, years of experience, and quality of instruction. More specifically, in order to be considered for this study, teachers had to be actively involved in program development, they needed a minimum of 10 years teaching experience, and they had to have been recognized publicly for meritorious teaching. Mrs. Thompson ${ }^{2}$ was primarily responsible for the revision of the physical education curriculum and the writing of the district physical education guide. Ms. Petersen was involved in the development of a new physical education program based on a movement curriculum model. Ms. Blanchard was at the time of this study serving on a 4-year curriculum evaluation team for $\mathrm{K}-12$ physical education in her district. Each teacher had worked with student teachers on a regular basis and had received commendations from the university school of education for her expertise. All three had master's degrees (from different universities) and from 14 to 20 years of teaching experience in elementary physical education. All three teachers had received outstanding teaching awards in their districts based on supervisor and colleague evaluations.

\section{Elementary Physical Education Programs}

Although the demographic variables for the teachers were similar, the three programs had distinct characteristics which became evident through field studies, interview, and document analysis.

Mrs. Thompson's Program. Mrs. Thompson's program was conducted in a suburban elementary school 10 miles from a major metropolitan area. Students represented a combination of rural children from a small midwestern farming community and children whose parents worked in town. Less than $3 \%$ of the students represented minorities. The school received the U.S. Department of Education citation, Excellence in Educational Achievement, during the 1985-86 academic year. Schools were selected for this award based on effective utilization of resources and response to student needs. The citation indicated that the school had made excellent progress in both reading and mathematics achievement as well as in overcoming obstacles and sustaining progress in a variety of other disciplines.

The kindergarten through sixth grade physical education curriculum at this school was based on a games activity model that has been prominent in physical education since the 1920s (Jewett \& Bain, 1985). Instruction was organized around sport skills and included a sequence of skill teaching, practice, and game play followed by a tournament. This progression remained constant for units such as volleyball, softball, basketball, and soccer and was varied slightly for activities such as swimming, gymnastics, and dance. Students were grouped by homeroom, sex, or ability level. Content in Mrs. Thompson's program centered around skill

${ }^{2}$ All proper names used in the article are pseudonyms. 
work with most skill feedback of a specific nature. Class time was spent in skill practice or in group games.

Ms. Petersen's Program. Ms. Petersen taught physical education in a "paired" school in a metropolitan midwestern city. The paired system was incorporated in this district to achieve court-ordered desegregation. In this plan two elementary schools were paired, one in an area of high minority concentration and the other in a predominantly white neighborhood. One school was assigned to serve all students in both geographic areas enrolled in kindergarten, first, and second grades. The other school served third-through-fifth-grade students. Some $33 \%$ of the kindergarten-through-second-grade students in Ms. Petersen's classes represented minorities: 20\% Afro-American, 7\% Asian, 4\% Hispanic, and 2\% Native American.

Ms. Petersen's curriculum was structured to promote movement themes and fundamentals in a developmental approach. The professional preparation textbook, Physical Education for Children: A Focus on the Teaching Process (Logsdon et al., 1984) was the principal source for the curriculum. Ms. Petersen had studied with one of the textbook authors and had confidence in her ability to implement this approach in her classroom. This curriculum emphasized the content categories of spatial and body awareness, the use of force, effort, and maneuvering weight, and the relationships of movers to each other, equipment, and boundary limitations. The teaching style incorporated open-ended directions that allowed students to select from a variety of options.

Ms. Blanchard's Program. Ms. Blanchard's school served the faculty and graduate student housing complexes for a major university in a midwestern metropolitan area. The university attracted large numbers of foreign students into its graduate programs. An examination of the population of this elementary school indicated that these kindergarten-through-fifth-grade students represented 53 countries and spoke 44 languages or dialects. Many students spoke no English during the first weeks of school and primarily copied the behaviors of other students in physical education. These imitations consisted of both on-task and off-task behaviors. The school was located near an affluent, predominantly white neighborhood, contributing to the multicultural atmosphere.

Like Ms. Petersen's program, Ms. Blanchard's curriculum was based on the Logsdon text. She had also studied with one of the authors (though different from Ms. Petersen's mentor) and felt that she was still learning to teach the content advocated in this approach. Ms. Blanchard's master's thesis had been specifically concerned with decision-making opportunities for students, and she was quick to emphasize this component of her curriculum with the observer. Students were given opportunities to make decisions about the content (i.e., which movement to use in a routine or a particular strategy to incorporate in a game situation). Students could also choose different size, shape, or weight equipment and were encouraged to analyze the unique characteristics of each. For example, mechanical principles of projection, reception, and optimal angle of flight were discussed and the information was used in making equipment decisions or in developing game strategies. Decisions were permitted regarding working space and peer interactions. Whenever students were included in the decision-making process, they were encouraged to consider the consequences of their choices. 


\section{Design}

The research design used the five curriculum domain perspectives as a structure for the data collection and analysis. A content analysis was used to analyze the professional textbook (ideological domain) and the curriculum guides (formal domain) adopted by these districts. Interviews were conducted with teachers and students in the perceived and the experiential domains. Field notes provided a record of events in the operational domain.

Data Collection. Three separate procedures-observation, content analysis, and structured interviews-were used to collect data in this study. A time line for data collection is provided below. Data collection procedures were sequenced so that observation occurred first, followed by the content analysis and interviews. This order was selected to minimize bias to the observer's perspective and build interview questions that were valid within the school settings examined.
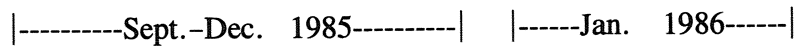

|-----Feb. 1986
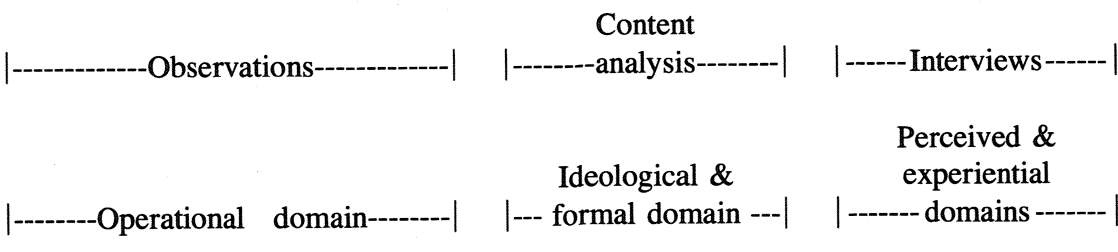

Observation data (operational domain) were collected by the investigator as a nonparticipant. Eleven physical education classes were observed each week over a 9-week period. Data were collected in four classes in both Mrs. Thompson's and Ms. Petersen's programs and in three classes in Ms. Blanchard's program. The observation schedule consisted of one class each of kindergarten, first, fourth, and sixth grade and two classes of second, third, and fifth grade physical education. Field-note data focused on observable events associated with content, instruction, class interactions, and evaluation. Data were recorded on an NEC 8201A lap computer. Following each observation, notes were rewritten and stored in permanent computer files (IBM-PC).

A content analysis of curriculum documents (ideological and formal domain) was conducted using a three-part procedure described by Klein (1982). First, the documents were perused for statements related to philosophy, content, instruction, and evaluation. Second, statements were recorded using the exact wording from the document. Finally, each statement was coded to reflect the major emphasis.

Interviews were conducted with teachers (perceived domain) and students (experiential domain) to examine participants' perspectives on the programs. Interviews were formally structured ${ }^{3}$ and utilized an open-ended format (Patton, 1980). Teachers were interviewed at the conclusion of the study. Interviews lasted

${ }^{3}$ Structured interview questions for teachers and students are available from the author. 
approximately 1 hour and consisted of demographic, programmatic, and philosophical questions. Follow-up questions or probes were used to encourage teachers to elaborate their perspective. Interviews were audiotaped and transcribed for analysis.

Thirty students from the programs were interviewed at the conclusion of the observation period. Ten students from each school were interviewed using a structured interview format that encouraged open-ended responses. Students were selected in consultation with the physical education and classroom teachers. An effort was made to select students who attended physical education regularly and who had adequate verbalization skills to be comfortable in the interview setting. Students were interviewed within 5 days of the teacher's interview. Student interviews were conducted in a quiet place, usually an empty classroom. Interviews were transcribed for analysis. Student interviews lasted approximately 20 minutes and focused on two aspects of students' experiences in the physical education program: description of experiences and attitudes toward these experiences. Probing questions were also used with students to encourage them to elaborate their experiences within the physical education program.

Data Analysis. Data were analyzed using constant-comparison analysis (Glaser \& Strauss, 1967). Constant comparison is an inductive process that occurs in four phases: (a) comparing incidents and generating categories, (b) integrating categories, (c) delimiting the emerging theory, and (d) writing the theory. In the first phase, data from the field notes, content analysis, and interviews were analyzed separately to identify common elements or examples. Similar examples were then grouped and rescanned in the second phase to detect common properties in an integrative process. In the third phase, properties were compared across categories and domains to test the integrity of group membership, thus delimiting the emerging theory. Only categories and properties that were verified across domains were considered in the fourth phase (writing the theory).

\section{Results}

The three programs presented contrasts in participant perspectives concerning the nature of the content taught and learned in physical education. Each domain contributed a unique philosophical component that blended to form the holistic curriculum. Although results in each domain will be presented separately, data from other domains will be used at times to elaborate findings.

\section{Ideological Domain}

The three programs exhibited two distinct levels of complexity in the use of an external ideology. Mrs. Thompson's program was based on an activity curriculum that exemplified a sports and games curriculum approach. The other two programs incorporated the major curricular and instructional components of a movement curriculum model (Logsdon et al., 1984).

There was no formal documentation in the ideological domain to guide in the analysis of Mrs. Thompson's program. The ideological domain in this case was implicit and had to be analyzed indirectly from information available in other domains. All curricular documents were developed internally and were considered as part of the formal domain. Discussions with Mrs. Thompson (perceived domain) 
and data from field notes (operational domain) suggested that the program typified an eclectic model as demonstrated by the selection of a wide range of activities included in the curriculum, with sport and games as the central focus. Annarino, Cowell, and Hazleton have described eclectic programs as those used to "create a system by selecting from all sources those elements that are sound in logic and have proved most useful in education"' $(1980$, p. 55). This curriculum process reflects the activity centered curriculum that was in vogue in most subject areas in the United States in the 1920s and 1930s (Schubert, 1980) and that continues to be an integral part of physical education programs. At the elementary level, these physical education approaches are characterized by a curricular organization based on game or sport units that carry titles such as Lifetime Sports, Individual and Team Sports, Fitness, or Fundamental Movement. When organizing themes are present, they typically apply to selected units.

The programs developed by Ms. Petersen and Ms. Blanchard from the Logsdon movement education model were structured from a theoretical base published in the form of a professional textbook. The Logsdon curriculum is based on a conceptual model for human movement developed by Rudolph Laban (1971). This model serves as the foundation for the physical education curriculum based on educational games, dance, and gymnastics. Fundamental movement patterns are sequenced within this structure to provide a comprehensive series of progressions. The assumptions of the model emphasize the importance of the individual, a commitment to assisting students in reaching their potential, an understanding of movement skill, and an opportunity for shared decision-making. Physical education curricular models based on movement fundamentals have been available since the 1960s (Barrett, 1987).

\section{Formal Domain}

The formal domain represented the curriculum developed within the school system. Frequently this aspect of the program is designed by teachers within the confines of the ideological domain and may in fact be a subset of it. This was the case in the three programs examined in this study. In Ms. Petersen's and Ms. Blanchard's programs the curriculum guide reflected the terminology and categorical system inherent in the Logsdon framework. However, the guide was modified to reflect two important local concerns. First, the developmental emphasis of the teachers who volunteered to serve as authors was reflected in the proposed learning objectives and instructional tasks. Second, the guide was written for an audience of physical educators who had been trained through the sport and games approach. A glossary of terms from the Laban/Logsdon work was included as well as an emphasis on the conceptual or thematic approach to physical education. The guide provided an extensive set of enabling objectives for each theme within the program areas of games, dance, and gymnastics. These were followed by a limited set of exit level objectives. No other evaluation criteria were stated in the guide. The Logsdon text includes a chapter by McGee (1984) that provides guidance for evaluation. Although McGee stated the theoretical foundations or "positions" for evaluation as activity areas, movement elements, and learning domains (pp. 356-357), these were not explicitly included in the district guide.

The curriculum guide in Mrs. Thompson's program had also been recently revised. However, in this program the guide articulated the philosophy of both 
the implicit ideological and the explicit formal domains. The ideological philosophy was traced using the technique of curriculum mapping (English, 1980). In this procedure data from the content analysis are used to develop a table of specifications for the program. Components of the philosophy are traced through goals, objectives, and experiences to develop a mosaic of the intended program. In this curriculum, units were titled swimming, ball skills, tumbling, physical fitness, and low organized games. Also evident in the managerial section of the guide were goals directed toward listening, following rules and directions, respecting authority figures, responsibility for equipment, and personal hygiene.

The formal domain represented by the guide for Mrs. Thompson's program reflected the elementary school principal's philosophy of education as well as teacher-developed components. The strong emphasis on both general rules for all students and staff procedures for discipline suggested the influence of an authoritarian leader. For example, several elements of the guide were couched in the first person, reflecting the expectations of the principal for his staff: "I will assume that when you send a student to the office for disciplining that all other methods of dealing with the child have failed at this point and that this is a cry for urgent help" (p. 16).

Unlike the guide for the movement programs, the guide for Mrs. Thompson's program included an explicit section on evaluation. Although the philosophy and objectives emphasized in the guide were directed toward the development of skills and fitness, the evaluation procedure appeared to be based on student effort and participation rather than on skill or fitness achievement. Evaluation of skill level was based on a three-point scoring system: "3 pointsdemonstration of extra effort in class activities; 2 points-participating regularly in class activities; 1 point-not performing to his/her potential" (p. 10). In this interpretation of skill level, the participatory emphasis was the central criterion (Placek, 1984). A second category of evaluation in Mrs. Thompson's program was that of social behavior or group interaction skills. These included good attitude and effort, listening and following directions, and cooperation and safe participation. Again, positive participation was the primary goal explicitly evaluated.

\section{Perceived Domain}

Distinct differences among the teachers were evident when data were analyzed in the perceived domain. This perspective reflected teacher impressions of curriculum content and the rationale for its selection. Although all of the teachers valued instruction based on a wide range of content, each had a specific focus that she reported to be of primary importance. Mrs. Thompson emphasized teaching of listening skills, Ms. Petersen focused on motor skill development, and Ms. Blanchard stressed shared decision-making.

Mrs. Thompson indicated that listening was an important component for student safety, good citizenship, and the development of responsibility in her activity curriculum. Listening was listed in the guide with cooperation, sitting quietly, and sharing, although no specific enabling or exit level objectives were articulated. In the interview, Mrs. Thompson stressed the importance of safety in her classes. The second unit in the school year was swimming. She expressed concern that the large class sizes made controlling the elementary students in the 
pool a particular concern. The emphasis on listening skills stemmed in part from the need to focus students' attention on the teachers and aides in a noisy and sometimes crowded setting:

\begin{abstract}
We can only schedule the pool at the high school during the month of October because that is the only time that swimming is not being taught in the high school program. This means that we have two classes of 25 students in the pool with only two additional aides to help us. Because there is so much going on, it is important to be able to get and keep students' attention. I also want them to learn in my classes. We keep careful swimming records which follow the Red Cross guidelines. We are trying very hard to teach students the skills they need to know to pass the next level during the swimming unit. (T, R, 1037)
\end{abstract}

Mrs. Thompson explained that she emphasized listening skills from the first day of school throughout the school year. She described the characteristics of good listening as sitting quietly with eyes on the teacher when directions were being given, remembering and following directions, and concentrating on the directions even when the game was exciting.

Ms. Petersen, on the other hand, described herself as a developmentalist and placed an emphasis on the observation of skills and the structuring of tasks to accommodate a wide range of student developmental levels. She believed that it was the teacher's responsibility to teach the student how to observe and analyze movement:

In my classes even the youngest students learn to observe fundamental movements and judge whether movements are being performed correctly. Each pattern or skill is taught with a set of criteria which assist the child to evaluate his or her own performance. (P, F, 813)

She listed several methods used to remind students of the observational criteria, such as verbal repetitions, pictures, and wall posters. She asserted that the observation of movement was important in evaluating both one's own movement and those of partners and other group members.

Ms. Petersen strongly emphasized the use of developmental tasks to provide an inclusive environment for all students. She explained that once students had learned to compare their performance with the criteria, they were able to function successfully at a developmental task station. Within the station there were frequently several different tasks representing a range of difficulty. Over a period of several weeks, students were taught to analyze their performance based on verbal or posted criteria. When the quality of movement matched these guidelines, students could decide to move to the next most difficult task within the station.

Although both Ms. Petersen and Ms. Blanchard had been trained using the same ideological curriculum, they differed in their emphasis on specific content components. The most important function of education in general, and physical education in particular, in Ms. Petersen's program was to aid the developmental process and assist students in becoming skillful movers. This emphasis was also 
present in Ms. Blanchard's program, but it was blended with the mission of teaching children through the decision-making process. Interviews with Ms. Petersen indicated that the age and experience level of her students $(\mathrm{K}-2$; paired school) limited her use of decision-making tasks. She supported the use of decision making and reported that this had been a stronger component of her program when she had taught at other schools and with older students. Ms. Blanchard described the emphasis on decision making in her classes as teaching her students to be responsible for themselves and their movement decision:

It is very easy to get into the habit of telling students what you want them to do and how you want them to do it. While I know that I give my students a lot of directions, still I try to build options into the tasks so that they can decide based on their interests or abilities. Just as important are the decisions related to movement: under what circumstances do you keep the ball and dodge and when do you pass it to a teammate? I work really hard to create situations where students have to make decisions. In this way they get to learn firsthand the advantages of good movement choices. (B, H, 674)

Ms. Blanchard also said that she considered "incorrect decisions" to be a very important part of the decision-making process. Behavior that would have been categorized as off-task by others was classified as "the consequences of making an incorrect decision." Students were expected to learn from their mistakes and correct the behavior without intervention from the teacher, especially with selfmanagement decisions. Although each teacher had a specific focus, all agreed that the curriculum should incorporate listening, skill development, and decision making. The differences lay in the comparative emphasis on each component and the amount of reflective thinking and consequent planning that was expended to implement these goals.

\section{Experiential Domain}

The students in Mrs. Thompson's program perceived a wide range of content. They indicated that movement and fitness skills, games, and swimming strokes were experienced in their classes. Listening was an important process or instrumental goal for students. Students acknowledged that success in activity and class privileges were contingent on attentiveness and following directions. Students in Ms. Petersen's kindergarten, first, and second grade classes described content specifically within categories of locomotor movement such as running, crawling, rolling, and sliding. They described using different movements, pathways, levels, directions, and balances to make sequences and to travel through obstacle courses. They also recited the rules for listening and "not hurting other people." These young students generally described movement education curricula as "ways to move" rather than "things to do," as did Mrs. Thompson's students.

Ms. Blanchard's students described their physical education content in terms of concepts related to use of space and relationships. They enthusiastically described modified games in which they practiced dodging and intercepting. Behavioral goals were associated with characteristics of good game "players" emphasizing sportsmanship and concern for others. Decision-making, like listening in Mrs. Thompson's class, was perceived by students to be a process or an instru- 
mental goal. Students who made "good" decisions about content were perceived to be more successful and were evaluated more positively by peer judges during group demonstrations than those who used "boring combinations" of skills.

\section{Operational Domain}

The operational domain is typically considered the curriculum in action. Although these data were collected first in the study, they were not fully understood until data from other domains were analyzed. The insights from the documents and interviews were used to provide the philosophical rationale for the series of decisions and interactions that were observed in this domain. The emphases examined in the ideological, formal, and perceived domains were implemented as the curriculum was conveyed to and encountered by the students in the operational domain.

Mrs. Thompson emphasized the importance of listening on the first day of class, stressing that good listening skills were required for future units involving swimming and that individuals who did not listen would not be allowed to stay in the pool area. She reinforced this by drills in the gym related to complex sets of directions requiring both attentiveness and auditory memory. Field-note data documented that this focus diminished slightly after the first 6 weeks of school and at the completion of the swimming unit. The social responsibility theme continued, however, with an emphasis on conformity to the rules, responsibility for self-management, and teacher-appointed leadership. This attitude reflected the social transmission orientation of preserving the existing society and training students to work within governing structures. Rules were stated clearly, and the rationale and consequence of deviance were discussed. Students were expected to give maximum effort and participate as a member of the class society. The social transmission orientation was perpetuated through the rules structures, the teacher as the enforcer of the rules, and the importance of working cooperatively with other society or class members to achieve common goals (Apple, 1979; Giroux, 1981).

Ms. Petersen's emphasis on skill observation and developmental task sequences was evident in every lesson that was observed. Specific skill tasks were organized to encourage students to exhibit progressively more advanced levels of performance. Although no ideal standard of performance was indicated, students were encouraged to evaluate their own performance based on specific criteria for skillful movement. Ms. Petersen constantly monitored and analyzed the movement, intervening with students to suggest a change or to encourage a new, more difficult challenge. Kindergarten-through-second-grade students in Ms. Petersen's classes were not only expected to perform skillfully but were also encouraged to cognitively understand and verbally respond to questions related to recall of movement terms, application of learned skills in new situations, and the synthesis of movement skills into sequences.

Ms. Blanchard's focus on decision-making was observed throughout her lessons. Third-through-sixth-grade students in Ms. Blanchard's program were consistently encouraged to make decisions regarding content and self-management. Content decisions emphasized cognitive selection of skills to solve movement problems, explore alternatives, and associate specific movements with desired outcomes. Self-management decisions were related to personal responsibility for 
listening, following directions, and working constructively with others. Decisions were considered privileges, which were given equally to every class member but could be withdrawn when one or more students demonstrated that they could not act responsibly. The exceptions to this policy were the non-English-speaking students who required additional assistance in understanding decision-making opportunities. There was a greater evidence of off-task behavior in Ms. Blanchard's program than in either Mrs. Thompson's or Ms. Petersen's. Although part of this behavior could be attributed to non-English-speaking students, the interview with the teacher acknowledged that some off-task behavior was associated with the decision-making process.

\section{Discussion}

Analysis of data across domain suggested that perspectives provide important insights into the interactive nature of a curriculum. In these programs, the ideological domain was the most influential curriculum perspective. In the Petersen and Blanchard programs, the ideological emphases on the Logsdon curriculum model served as the explicit organizing structure for curriculum decisions in the formal and perceived domains. These teachers had been trained in the use of the ideology through mentoring with the curriculum designers. Both teachers advocated the assumptions of the model and worked conscientiously to structure class experiences to be consistent with this philosophy. Although there were local additions to the curriculum (formal and perceived domains) related to implementation of the developmental emphasis, the ideological philosophy remained intact.

The influence of the ideological perspective in Mrs. Thompson's program represented a tradition in physical education that has evolved over a 60 -year history. The eclectic nature of content selection, the organization of experiences around sport and game activities, and the participatory focus of evaluation suggested that the sport and games model was the implicit foundation of the Thompson program. This philosophy was further elaborated in the curriculum guide. Local modifications for specific sport emphases did not change the character of the model. Furthermore, the perception of the teacher that this represented the optimal design for students in her program confirmed the influence of this ideology on the perceived perspective.

The analysis of perspectives by domain revealed two concepts that crossed domains in these programs. These were the use of decision-making regarding content, equipment, and self-management and the cognitive involvement of students with the content. Both concepts represent aspects of cognition and reflect curricular variables that facilitated the implementation of the philosophy and content in these physical education programs.

\section{Decision Making}

The structure of Mrs. Thompson's sport and games classes permitted decisions in the self-management area. Students received instructions about appropriate skill performance as well as the location in the gym or on the field where the practice was to occur. The most common decision given to students involved with whom they could work. Mrs. Thompson considered this a privilege granted to students who were good listeners and workers. 
Ms. Petersen shared a variety of content decisions with her students. Kindergarten, first, and second grade students were permitted to select movements required to solve problems such as those related to sequence or balance. She discussed the directions for problem-solving with students, emphasizing that there were many different ways to arrive at the right answer, in her words, "some of them I haven't even thought of!" For example, she encouraged the children to move through the obstacle course solving the balancing, rolling, mounting, and dismounting problems using each "movement idea" only once. There were specific tasks or problems to be solved at each learning center. Multiple solutions were encouraged. Students were praised based on both the quality of the movement and their ability to arrive at a novel solution.

Conversely, equipment and class management decisions were frequently structured by Ms. Petersen to assist students in learning content. Most decisions were made by the teacher. Equipment was to be used in specific ways and constituted task cues for the job to be performed. For example, when bicycle tires, ropes, and mats were spread randomly around the gym, students learned that they were to jump into the tires, hop over the ropes, and roll along the mats. These same equipment cues were used in later units to teach more complex movement patterns. For instance, a tire was placed in front of the vaulting bench to remind students that they were to use a jump in preparation for all vaults. In this way, equipment served a specific function within the content emphasis of the class.

Many class management decisions were controlled by the teacher to facilitate good working conditions for learning movement skills. Although students were allowed to select classmates with whom they would like to work, groups were usually sent to particular centers by the teacher and told when to rotate to the next center. The skill emphasis identified in the ideological and formal domains, reported by the teacher in the perceived domain and the students in the experiential domain, was confirmed by the observer in the operational domain. Performance criteria and the emphasis on student decision-making were evident in numerous examples throughout the field-note data.

The data also confirmed the coemphases of movement skill and decisionmaking in Ms. Blanchard's program. Third, fourth, and fifth grade students in this program were given opportunities to make decisions regarding class management, content, and equipment. Class management decisions similar to those permitted by Mrs. Thompson and Ms. Petersen allowed students to decide with whom they wished to work. Ms. Blanchard also provided additional options, inviting students to choose where in the gym or field they would like to participate. Englishspeaking students were expected to make appropriate decisions and be attentive to class discussion. Students for whom English was a second language were permitted greater latitude and reprimanded only when behavior was disruptive.

Content decisions for the older elementary students in Ms. Blanchard's program involved the exploration and understanding of effective movement strategies. For example, in an educational games unit on intercepting, students experimented with different strategies for masking their behavior or simulating one movement while actually preparing to perform another. Class discussions involved the association of a strategy with the appropriate situation. Equipment choices were used both to increase the understanding of the content (e.g., adaptation of a movement necessary for different equipment) and to allow students to work with a 
preferred object. Equipment decisions related to content were an intricate part of many experiences, as students were encouraged to throw and intercept balls of different sizes, shapes, and weight. In the lesson on intercepting, adaptation for angle of projection, force, and weight also were considered in the selection of an effective strategy.

\section{Cognitive Involvement}

In this study one of the major differences between the program based on the traditional approach and those based on the Logsdon model was the emphasis on the cognitive involvement of students. In the Logsdon model, students were asked to examine characteristics of movements and make decisions regarding effective use of different movements based on context. Students were also required to recall, synthesize, and evaluate movements within both of these programs. Teachers using the Logsdon ideological curriculum are encouraged to employ the terminology of the model. They may write terms on the blackboard or make posters and refer to them to explain a movement. In the Petersen and Blanchard programs, students were exposed to general movement terminology such as locomotor and nonlocomotor as well as the specific skill components of these two categories.

In Ms. Petersen's class, first grade students were asked on the first day of school to recall the seven locomotor patterns that they had learned and practiced in kindergarten. These students were later taught to further classify movements into flying, crawling, stepping, and rolling categories based on specific criteria. The majority of these class periods were spent in careful analysis of the components of a movement pattern. Students provided both verbal and motor explanations to support their assessments. Kindergarten, first, and second grade students were later asked to synthesize several movements to form a sequence or to combine movements into a routine. Class members were then encouraged to evaluate these demonstrations to determine whether movements were performed and combined according to directions.

Similar cognitive experiences were provided in Ms. Blanchard's program with older elementary students. In an educational dance unit, students were challenged to recall the qualities of good composition that they had learned in drawing classes taught by a visiting artist. They were encouraged to analyze and apply these qualities to movement. Students were then asked to use movement to contrast two different lines and combine them into a routine that would emphasize the differences to an audience. Class members were asked to evaluate routines based on criteria such as clarity and quality of the movement. The cognitive components of these classes were carefully planned to convey an understanding of movement to these children. This emphasis was elaborated as a part of the ideological Logsdon curriculum and was confirmed in the formal, perceived, experiential, and operational domains. The cognitive component was less evident in Mrs. Thompson's program. Students were given written tests covering the material, especially in the swimming unit, but they were not asked to do more than recall the criteria of an effective performance described in the preceding class. Most of the analysis, synthesis, and evaluation of movement was conducted by Mrs. Thompson. 


\section{Conclusion}

The curriculum in these school settings was a complex blend of participant perspectives. Each perspective made a unique contribution to the holistic educational environment. The ideological domain, when articulated carefully as in the Petersen and Blanchard programs, provided the guiding structure for the conceptualization of the formal and perceived domains. When unspecified, other perspectives, typically formal and perceived, became more explicit in the structural design. Ideally, the formal domain (curriculum guide) serves as a liaison between the ideological and the perceived perspective, translating the philosophy into enabling objectives that bridge the philosophy-practice "gap" (Kneer, 1986).

Curriculum perspectives emphasize multiple components of a curriculum without ignoring the relationships among them. Efforts to modify existing models and implement alternative curricular approaches should begin with an understanding of ideological, formal, and perceived belief structures. Experiential curriculum concerns should be addressed with a sensitivity to the multitude of student experiences that include, but are not limited to, achievement. School officials have become increasingly aware of the importance of including many perspectives as they design and implement curricula. It is essential that educational research designs expand with similar propensity to represent the multiple perspectives inherent in school settings.

\section{References}

Annarino, A.A., Cowell, C.C., \& Hazleton, H.W. (1980). Curriculum theory and design in physical education. Prospect Heights, IL: Waveland Press.

Apple, M.W. (1979). Ideology and the curriculum. Boston: Routledge \& Kegan Paul.

Apple, M.W., \& Beyer, L.E. (1983). Social evaluation of curriculum. Educational Evaluation and Policy Analysis, 5, 425-434.

Barrett, K.R. (1987). The subject matter of children's physical education or no gap to bridge-no race to run. In M. Carnes \& P. Stueck (Eds.), Proceedings of the fifth curriculum theory conference in physical education (pp. 211-223). Athens: University of Georgia.

English, F. (1980). Curriculum mapping. Educational Leadership, 37, 558-559.

Ennis, C.D. (1985). Purpose concepts in an existing physical education curriculum. Research Quarterly for Exercise and Sport, 56(4), 323-333.

Giroux, H. (1981). Ideology: Culture and the process of schooling. Philadelphia: Temple University Press.

Glaser, B.G., \& Strauss, A.L. (1967). The discovery of grounded theory: Strategies for qualitative research. Orlando, FL: Academic Press.

Goodlad, J.I., Klein, M.F., \& Tye, K.A. (1979). The domains of curriculum and their study. In J.I. Goodlad (ed.), Curriculum inquiry (pp. 43-76). New York: McGraw-Hill.

Goodson, I. (1985). History, context and qualitative methods in the study of curriculum. In R.G. Burgess (Ed.), Strategies of educational research: Qualitative methods (pp. 121-151). Philadelphia: Falmer Press.

Graber, K. (1988, April). Making the grade: A qualitative study of teacher preparation. Paper presented at the meeting of the American Educational Research Association, New Orleans. 
Hellison, D. (1985). Goals and strategies for teaching physical education. Champaign, IL: Human Kinetics.

Jewett, A.E., \& Bain, L.L. (1985). The curriculum process in physical education. Dubuque, IA: Wm. C. Brown.

Klein, M.F. (1982). State and district curriculum guides: One aspect of the formal curriculum. A study of schooling in the United States (Report No. SP 019 816). Los Angeles: UCLA School of Education. (ERIC Document Reproduction Service No. ED 214 879)

Kneer, M.E. (1986). Description of physical education instructional theory/practice gap in selected secondary schools. Journal of Teaching in Physical Education, 5, 91-106.

Kolb, D.A. (1983). Experiential learning: Experiences as the source of learning and development. Englewood Cliffs, NJ: Prentice-Hall.

Laban, R. (1971). The mastery of movement (3rd. ed.) (Revised by L. Ullman). Boston: Plays.

Logsdon, B.J., Barrett, K.R., Ammons, M., Broer, M.R., Halverson, L.E., McGee, R., \& Roberton, M.A. (1984). Physical education for children: A focus on the teaching process. Philadelphia: Lea \& Febiger.

McGee, R. (1984). Evaluation of processes and products. In B.J. Logsdon, K.R. Barrett, M. Ammons, M.R. Broer, L.E. Halverson, R. McGee, \& M.A. Roberton, Physical education for children: A focus on the teaching process (pp. 356-421). Philadelphia: Lea \& Febiger.

Patton, M.Q. (1980). Qualitative evaluation methods. Beverly Hills, CA: Sage.

Placek, J.H. (1984). A multi-case study of teacher planning in physical education. Journal of Teaching in Physical Education, 4, 39-49.

Schubert, W.H. (1980). Curriculum books: The first eighty years. Washington, DC: University Press of America.

Wang, B.M. (1977). An ethnography of a physical education class: An experiment in integrated living. Unpublished doctoral dissertation, University of North Carolina at Greensboro.

Zeichner, K.M., \& Tabachnick, B.R. (1983, April). Teacher perspectives in the face of institutional press. Paper presented at the meeting of the American Educational Research Association, Montreal. 